\title{
Technology and the dis-placing of learning in educational futures
}

Charles Crook ${ }^{a}$

a School of Education, University of Nottingham, Nottingham, NG8 1BB, UK

Charles.Crook@nottingham.ac.uk

(Corresponding Author)

Brett Bligh ${ }^{b}$

b Department of Educational Research, Lancaster University, Lancaster LA1 4YD, UK

B.Bligh@lancaster.ac.uk

\begin{abstract}
Common visions of online education entail radically re-configuring the experience of learning: a technological displacement from the spatial order of classrooms into the more diffuse arena of digital networks. One assumption seems to be that that very spatial order of classrooms creates an undesirably rigid sense of place for schooling, one that is depressingly impervious to change; and that the attendant solution is to escape the realm of the 'physical' altogether - into an online realm more supportive of collaboration and free of face-the-front conventions. In the present paper we seek to challenge this oppositional view. We consider several ways in which digital technology can restructure the traditional spaces of educational practice, and identify design dynamics that may be neglected in the wake of 'virtualisation'. Discussion first highlights two theoretical perspectives that will inform many such designs: namely, situativity and sociality in learning. Three examples are then provided of how digital technology can intersect with learning space design to create novel interpersonal frameworks for learning and to destabilise conventional senses of 'place' in those settings. The examples concern, respectively, the organisation of collaborative, expository, and community-based social structures for learning. Those examples represent an illustrative counterpoint to models of online schooling and illustrate a potentially productive synergy between the opportunities afforded by digital technologies, the desires of those who wish to dis-place learning online, and a well-established interest in learning space design.
\end{abstract}

Keywords: learning spaces, classroom design, online learning

\section{Introduction}

There have always been voices of discontent surrounding the institutions of schooling. It is certainly right that designs for education should face critical attention. Yet here and there such critique has bubbled up to question the very fabric or existence of the school as we have come to understand it (Bowles and Gintis, 1976; Freire, 1986; Illich 1973; Reimer, 1971; Shantz, 2012). Currently, such radical critics are being offered one possible basis for an alternative future. Digital networking is increasingly considered an intriguing means of transforming the experience 
of education: doing so by making possible a "global learning infrastructure" (Heterick, Mingle and Twigg, 1995). To be clear, enthusiasts of technology in learning have hardly needed to wait for the advent of the web to advocate subverting traditional schooling by embedding it into wider structures - viewed as more 'authentic' due to their connections to practices happening outside educational institutions. Witness the twentieth century 'teaching machines' of Pressey and of Skinner, and the programmed instruction of the latter, where the stated intention is to disrupt 'primitive' relations between the teachers and the taught: this as part of an educational "industrial revolution" to involve bringing learners into direct personal contact with external creators of societal content (Benjamin Jr., 1988). Or consider the 'learning machine' initiatives of Papert and colleagues that sought inspiration from more informal kinds of cultural activity and perhaps to remove learners from school venues altogether (find more discussion of relations between 'formal' and 'informal' in Crook and Lewthwaite, 2010). Yet the present paper notes how, in contrast to those earlier visions, online learning has actually increasingly flourished, not least because its designers have deftly appropriated a modern perspective on learning, one that conceives it in strongly 'social' terms that seem to intuitively dovetail with some of those wider critiques of the educational theorists we mentioned above. By way of contrast, in the present paper we consider here how the sociality within more conventional classrooms might be similarly transformed, through a parallel coordination of technology and space - while noting the limited extent to which this possibility has been pursued.

Stripped to essentials, the most familiar patterns for schooling involve a curriculum to be experienced at a particular time (stereotypically: 'early life'), located in distinctive sorts of places ('schools'), and orchestrated through a particular social dynamic ('teaching'). Moreover, in contrast to informal instruction, this curricular instruction often manifests long term goals (such as induction to literacy and numeracy practices) in which are constructed cognitive and interpersonal skills that seemingly have no 'natural' grounding in everyday life.

As we shall discuss further below, the very familiarity of those conventional structures can be taken to indicate a shared educational culture, but also to hint at the immutability of that culture. Learning online, on the other hand, is seen as disturbing all of these structures. Episodes of social engagement are more typically asynchronous, participation is less spatially prescribed, and the interactions of learning are more often student-led (Katz and Oblinger, 2000; Searson, Monty Jones, \& Wold, 2011). As critical scholars, and perhaps as individuals grounded in a more conventional educational culture, if the abrupt transformations of education that such designs promise do not leave us incredulous, they may well leave us uncomfortable. However, the purpose of the present paper is not to question the credibility, or even the desirability, of this prominent 'dis-placing' of educational practice (cf. Jandrić, 2014). Its purpose is more one of constructing a counterpoint to such a possible future. Our concern around this matter hinges on the general question of how technology re-mediates the management of place and social interaction, even within those more traditional educational contexts where the implications have received less attention.

One particularly compelling consequence of full-strength online learning is that technology brings about significant shifts in the social relationships of learning; one way in which it does so is by radically dis-placing those relationships - undermining the familiar spatial context. So we consider here how contemporary technologies can mediate fresh social interactions by similarly 
re-configuring the spatial structures within the more conventional, or traditional, sites of teaching and learning. We wish to notice emerging opportunities to destabilise the 'traditional', thereby positioning those traditional settings of education as complementary of online modes rather than in jealous and conservative opposition. Moreover, we suggest that these neglected design possibilities offer valuable opportunities for enriching future educational practice in school settings.

In the first section below, we highlight those forms of educational critique that often serve to attract interest towards the potential of online learning as a format for future education. The prospect is set against two theoretical frameworks for understanding human cognition and learning: situativity and sociality. We then furnish some case illustrations, drawing heavily on our own work, so as to indicate how it is not only within online education that technology can reconfigure spaces to influence learning relationships: technology can also shape productive interaction in conventional classrooms through the way in which it is integrated with spatial design.

\section{Temptations to embrace a virtual schooling}

Learning is an inevitable and ongoing human process. While it may be difficult to inhibit or precisely control, learning may be readily intensified, motivated and directed towards predetermined goals or values. That is, human cultures have evolved interactions that are organised such that learning is the explicit purpose: strongly driven by intentionality, and typically disconnected from the learner's immediate needs. 'Education' connotes the cultural practice that has emerged to manage such activity. 'Schools' are then the dominant places for this education to happen. 'Study' is what ostensibly gets done in those places: namely, the engagement of deliberate learning.

Here is a simple exercise: enter the term 'studying' into a search engine but request the output as 'images'. The result will suggest the following themes: boredom and stress, a socially isolated practice, an expository engagement (mainly with books), and activity anchored to sites specialised for the exclusive purpose of formal learning (e.g., libraries, personal 'studies', and classrooms). For sure, the search engine montage is an imperfect way of diagnosing the state of some cultural practice. Yet these visual associations resonate with a modern unease. They certainly encourage critically evaluating the learner-appeal of our educational designs.

Many educational theorists have long shared this unease (Claxton, 2013; Gee, 2004; Warmington, 2015) but the attendant dissatisfaction has recently extended into more open arenas of educational debate (e.g., Putnam, 2015; Robinson, 2006). This more popular concern is not only with the apparent lack of engagement or enthusiasm among many students; it also questions the very nature of the output - schooled knowing and schooled knowledge. One key strand of disquiet regarding knowledge acquired at school is its apparent lack of versatility. Once beyond the classroom, it is often found to be "inert" (Whitehead, 1929): that is, not applicable to life in some wider world, or not readily mobilised to be exercised there. Put another way, it has not been made sufficiently 'relevant'. The common route for those expressing such concerns is towards advocating educational practices that are more connected to, or embedded within, the wider cultural or economic world. Some variants of this critique dwell upon particular visions 
of the wider world, invoking a dissonance between what is achieved in school and the particular demands of modern 'knowledge economies' (Drucker, 1992; Lundvall, 1992). In the background are perspectives such as 'new growth theory' (Solow, 1994), which insists that economic development is now dependent on innovation arising from 'knowledge work' (Autor, Levy, and Murnane, 2003; Goodfellow, 2007). Note how that view of the wider world serves as harbinger for performative demands on learners (innovate, contribute economically, etc.). Although the more brazenly performative attitudes to schooled knowledge are widely contested, they can be disarmingly softened when presented in terms of the need for school leavers to have a greater confidence around analysis, criticality, and creativity. Surely, who could oppose the cultivation of such desirable qualities? Though exactly what those qualities entail and how they are acquired in the concrete is less aphoristic. The significant point at present is that a 'relevance critique' will often doubt the effectiveness of traditional schooling for delivering them (e.g., CBI, 2012). Here is a typical example of the anxiety that underpins contemporary proposals for reform: "How do we re-conceptualise learning to move beyond passive student roles of recording and recalling, because the world beyond the school walls demands adaptive, creative problem solvers?" (Zmuda, Ullman and Curtis, 2015, p.6).

Moreover, while such critiques may seem to target shortfall in the cognitive domain, they also invoke a failure in the more interpersonal domain: that is, failures in areas of 'social' intelligence. So it is often asserted that schooling must better equip students with an appreciation of how real world knowledge is built through collaboration, networking, and team-based thinking. It has become commonplace for employers to regret the limited capability of graduates for cognitively coordinating with others (CBI, 2009). Moreover, the individual's role in the modern workplace is increasingly understood in terms of their participation in "communities of practice" (Wenger, McDermott and Snyder, 2002) rather than in terms of individual actors located within contained processes of production (Brown and Duguid, 2000).

A consequence of all this uneasiness is an appetite for a greater 'open-ness' in educational design. It is argued that the school itself could surely be re-conceptualised to reach into the wider environment, whereby learners might have more vivid and dynamic encounters with those cultural practices within which knowledge building and sharing are embedded. Yet the practical implications of extending school life (physically or socially) into communities in any strong sense seem daunting. Accordingly, for the builders of future educational scenarios, these considerations have suggested one particular route towards such diversification that does seem more realistic. They suggest a form of reaching out that is more virtual in character: imagining that learning will increasingly be offered, managed, and enjoyed within the communication infrastructures of digital networking. In terms of our interest here in 'learning and place', such developments seem to converge on the promise that learning might become relatively 'placeless'. One expert review of these matters concludes:

As young people spend more and more time surfing the net, accessing virtual libraries, conferencing with their teachers via the web and publishing their work electronically, the traditional classroom as a setting for learning is quickly becoming redundant. (Building Futures, 2004, p.12)

Learning pursued within some such fabric of social media is a widely-explored way to consider future learning-in-its-place. It evidently suggests a basic challenge to our current experience of 
the school as a core site for learning. The traditional functions of school might thereby be 'unbundled' (Hagel and Singer, 1999; Rizvi and Lingard, 2010). So the processes of curriculum design, exposition, assessment, collaboration, mentoring, participation in practice, etc., become organised through outsourced or self-managed patterns of networked delivery and communication.

The circumscribed and unchanging character of the school, as a place, has made it an easy focus for agitating such reform. Its visible spaces and rituals simply offer easier points of reference for critique than do doubts about such abstractions as 'schooled knowledge'. We feel we can see the problem in the very furniture of education. Recruiting new digital technologies into the orbit of contemporary unease is, then, very tempting. Apart from technology's promise of a communication infrastructure that dis-places learning from the physical (and potentially oppressive) premises of school, these technologies are celebrated for cultivating a more radical sense of what knowledge is: namely, something negotiated, shaped and shared. Moreover, many political visionaries have confidence in technology, because they notice young people's receptivity towards it. The colourful-if controversial-phrase 'digital natives' (Prensky, 2001) is frequently used to carry arguments that educational innovation must exploit this technology to create flexible modes of learning and, thus, a flexible conception of knowledge; it is asserted that present generations of learners will be increasingly impatient with those educational practices that do not have digital media at their core.

\section{The situated and the social nature of learning}

The previous section observed the attractions of radically dis-placing educational practice. Discussion hereafter is not intended to undermine the vision of a more online, networked version of future schooling itself, so much as to highlight a potential lacuna: the assumption that the online and the networked will automatically render the physical obsolete. Perhaps that is more than an assumption - it is as though particular educational designers, frustrated that traditional venues for schooling are so apparently resistant to change, have become determined to abolish the very physicality of learning itself. We shall observe, on the other hand, that to displace educational practice does not necessarily mean to un-place it. The discussion will explore the general idea that social relations are shaped by spatial design, but that new technology is an overlooked force in re-configuring those designs. Adopting that focus resonates with two central ideas that underpin contemporary thinking around the psychology of learning - situativity and sociality - each of which will be considered below.

However, an immediate note of caution is necessary. When invoking such theory here it will be important to resist the seductive idea of learning as a generic characteristic of human activity (Young and Muller, 2010; Young, 2014): one whose singular nature might conveniently specify optimal designs for learning environments. There is no such over-arching theory of learning. Indeed the 'TIP' website ${ }^{1}$ identifies more than 50 distinctly different theories at the time of writing. While we do not suggest that all of those theories are equally valuable, or indeed imagine their underlying assumptions to be mutually compatible, together they prescribe a wide 
variety of ways of interacting with the world for the purpose of acquiring knowledge - each of which might be understood as a valid instantiation of 'learning'.

The point is that there are indeed many different ways in which interactions might be organised in the pursuit of some educational value. Our approach here is, instead, to "theorise" educational episodes in practice terms - as manifest, recurrent yet varying 'acts of learning' (Crook et al., 2010) - such as rehearsing, representing, playing, making, collaborating, etc. Those acts of learning will comprise a range of socio-cultural practices whereby learners creatively interact with their world. Such acts of learning are not theories in themselves, for they are decoupled from any grand, overarching theory - although they may each find inspiration in one or more of the 50 or so learning theories that are currently on offer. They do, however, represent different ways of coming to know. Moreover, through the learner's engagements, these acts of learning may distinctively shape the nature of the knowledge thereby acquired. Indeed, it is because of this choice in learning practices that flexibility in educational design is important. Problems encountered outside of schooling may occur in contexts that afford certain ways of knowing more readily than others. Similarly, problems to be encountered after schooling, such as structures of employment, may come to demand preferentially some ways of knowing over others. While resisting the notion that schools should simply be places that react to the external, the users of schooling certainly deserve a flexibility that might help to build a rich repertoire of relevant learning acts.

Such considerations spare us the temptation of considering traditional educational spaces in relation to some preferred generic theory of learning. However, there are still psychological universals to consider. In framing design ideas it is difficult to resist reference to certain psychological principles that are now widely recognised as underpinning human cognition and, thereby, human learning. Two will be identified here: the situated nature of cognition, and our human sociality. Grounds for arguing the universality of these two notions are derived from the entrenched trajectories of human biological and cultural evolution (cf. Donald [1991] for situativity and Tomasello [2009] for sociality). These two principles are each considered below and then deployed in the following section, where strategies for the enhanced design of traditional, co-present educational spaces ('classrooms') are discussed. Situativity is relevant to the present discussion because - if carelessly appropriated - it may suggest an inevitability to the networked and dis-placing educational futures outlined above. Sociality is relevant because it offers one particularly rich basis for re-thinking the mediation of learning activity in traditional educational spaces.

\subsection{Situativity}

Human cognition is now widely understood as 'situated' (Aydede and Robbins, 2009; Brown, Collins and Duguid, 1989; Lave and Wenger, 1990). At the root of this perspective is an insistence that thinking cannot be separated from 'doing' (Suchman, 1987): that mental life is embodied, and embedded, in the world. Our intuitive understanding of thinking (reasoning, reflecting, remembering, etc.) tends to ascribe such processes exclusively to a private mental arena. Yet a situated perspective locates cognition as mental activity intrinsically integrated with its immediate context: with an environment of things and people. The internal 'world' of the mental is looped into the external 'world' of the physical and, indeed, the very tempting notion to see those worlds as separated is deeply problematic in theoretical terms. In common practice, the 
recognition of this relationship invites managing learning in terms of optimising the potential of such a coupling: considering how the tools and designs of the external are most effectively integrated with the computational processes of the internal. The external world thereby becomes conceptualised by those designing learning practices as a repository of social and material resources to which reasoning, calculating, remembering, etc., can be partially or entirely outsourced. In short, human intelligence is the product of an evolutionary history whereby the mind is increasingly externalised into a heritage of cultural designs - a fact that educational designers attempt to appropriate with varying degrees of success.

Situativity is thus relevant to our present concern with the dis-placing of educational experiences, because as a framework it is easily invoked to suggest that learning must always be deeply embedded (or 'situated') in specific, subject-typical practices. So the best 'doing' for learners is doing that coordinates action with whatever cultural practices are traditionally associated with the subject being studied. Unsurprisingly, learning by apprenticeship is celebrated within this framework - and has inspired notions of a "cognitive apprenticeship" (Collins, Brown and Newman, 1989). Advocating such a perspective resonates with the commonly expressed concern (discussed above) that what gets learned in school is unhealthily fractured from an invoked 'real world'.

Yet creating a context that is fully faithful to some familiar cultural practice is a harsh requirement for respecting the situativity of learning. Making such a demand involves adopting a very strong sense of 'situated' that may be unwarranted. Firstly, learning can certainly, though not unproblematically, occur in relation to contexts that involve representations of familiar sites of practice. Secondly, learning can also occur through educational designs that recognise how particular aspects of practices, perhaps at the level of particular actions, are invariant, even if the wider practices themselves are situated. Take, for example, Greeno (1997), whose commitment to the principles of situativity is sufficiently strong as to cause him to prescribe apprenticeship models of learning. Greeno nonetheless suggests that instruction should draw attention to 'invariant' affordances of tools and collaborative activities where possible, so as to encourage learning about the range of situations in which particular affordances ought to be perceived, by learners, as relevant for their future activity.

As Bereiter (1997) has argued, what is so distinctive about human beings is that they are (uniquely) able to learn out-of-context. Learning that is "un-situated" (in any strong sense of that term) can, in principle, thrive in those special places (e.g., schools) where the human imagination can be stimulated to summon up (and investigate) worldly phenomena - outside of their natural ecologies. Indeed, Bereiter notes the practical obstacles that learners can often confront when they do directly engage with the contexts in which some disciplinary practice is exercised (particularly in school subjects such as physics, history, biology, etc.). Always striving to create such contexts risks burdening the learner with a very ponderous and complicated journey for acquiring subject confidence. The classroom can often reproduce the core processes of such constructive understanding with sufficient plausibility: mirroring the problem-based nature of real-world construction. But also by reproducing the relevant methods of research and inquiry, moments of collaborative working, and the practices of communicating and iterating around what gets to be known in the 'outdoors' reality of practice. The real challenge is therefore to 
equip the space of learning, howsoever contained, to allow for this "building of knowledge" (Scardamalia and Bereiter, 2006) by students.

How do these considerations relate to a future of dis-placed online education? Most simply, a discourse of situated learning may help underpin scepticism around the constraints of traditional classrooms, thereby building enthusiasm for education online as one prominent reaction. But, as suggested above, there are differing understandings of 'situated'. What might be termed an 'unqualified situativity' implies that disciplinary learning is best arranged as disciplinary participation - in the relevant disciplinary practices. Yet, what we might term the 'knowledgebuilding situativity' of Bereiter and colleagues appears, on the one hand, to acknowledge the basic mind-world coupling sense of situated cognition while, on the other hand, seeing the strict context dependency of such cognition as something that human beings "overcome" (Bereiter, 1997). This is achieved, in part, by "..creating a world of immaterial knowledge objects and acquiring expertise in working with them" (282). Yet it is not obvious that either sense of situated cognition is best honoured by exporting learning practices wholesale into a networked environment. First, simply contemplating the potential diversity implicit in Bereiter's 'knowledge objects' and 'expertise' immediately conveys that it would be challenging in many instances to offer and coordinate entirely online disciplinary participations of situated learning. While, second, if wedded too firmly to digital interactions, the situated and knowledge-building online learner risks being denied forms of educationally useful interaction that depend upon physical co-presence, access to material artefacts, and those forms of collaboration that might benefit from tacit or non-verbal communicative moves.

These considerations suggest that a recognition of the fundamentally situated nature of cognition intrinsically neither prescribes nor proscribes that an online format for education can grow to displace classroom-based practice. Instead, the pertinent consideration should be understood as how educational practices resonate with what is outside, or might come afterwards: through considering the commonality of action or representation, or by allowing and nurturing the possibility of learners overcoming the differences in situation. The venues of 'school', the sites of the 'authentic', the spaces of the 'online', the arena of the 'mental' - these start to seem less helpful as oppositions. Instead, they might better be conceptualised as interspersed, interrelated, interdependent - each mediated by various forms of 'technology', including in their relationships to each other.

However, the fundamental sociality of human learning is a different sort of challenge. Online learning is, by its networked nature, a very lively setting for social interaction - albeit, of particular kinds. Moreover, the design of such environments aspires to highlight such exchanges through its global reach for communication and resources, its striving for multi-modality, and through earnest claims for an 'always-on' character. Some of those aspirations contrast uneasily with common understandings of the typical school classroom, wherein critics detect an oppressive and didactic face-the-front tradition (Upitis, 2004). A consideration of formats for sociality-in-learning is offered in the next section.

\subsection{Sociality}


If perspectives on cognition and learning have lately taken a 'situated turn', they have also long taken a 'social turn' (Cole, 1990; Gee, 1992; Wells, 1999). The use of the term 'social' most correctly connotes something broader and more pervasive than directly gregarious interactions with others. Yet it is certainly the significance of interpersonal processes in educational practice that have become central to the deliberate development of designs for learning. Recent research (e.g., Tomasello, Carpenter, Call, Behne, and Moll, 2005) highlights a basic human motive for achieving shared understanding with others. Indeed, this motive is perhaps more fundamental to understanding the human condition of sociality than is dialogue, whether vocalised or written. Such broadly 'collaborative' orientations may be an important force for learning even before children enter school (Butler and Walton, 2013). Those insights reinforce a long-standing emphasis within educational theory on the importance of peer-coordination in learning (Crook, 1994; Damon, 1981; Johnson and Johnson, 1989). Designers of online learning spaces are alert to the challenge of organising that environment for effective peer collaboration. Accordingly, we shall consider below how digital technology might have a particular role in the configuration of a study environment for co-present learning, i.e., towards similar ends. Once again, we wish to challenge unhelpful conceptions of opposition.

The sociality of learning has also been highlighted in educational theories that dwell on more tutorial or instructional modes of interaction between students and teachers. The character of such interactions is sometimes simplified dichotomously in terms of "guide on the side" versus

"sage on the stage" scenarios (King, 1993). In short, this is a distinction that expresses different participative (Vygotsky, 1933/1978) and didactic qualities of the tutorial interaction. The design of learning online is sensitive to the need for managing the quality of this tutorial relationship - an issue often discussed, for example, in the context of Massive Open Online Courses (MOOCs), where tutor-student ratios are typically very high (Miller, 2015). Similarly, we shall be concerned below with how technology is implicated in the design of spaces that support tutorial as well as more expository forms of social interaction.

Finally, the sociality of learning can be resourced by designs at a higher level of institutional organisation: the structures of a 'learning community'. Indeed it may be because the discourse of learning online takes this notion very seriously that notions of community have become such a salient concern within traditional educational patterns (Goodyear, 2005). We consider below how the spatial design of traditional sites for learning can take this priority into account.

\section{The social construction of educational space}

It is often said about schools that, as occupied places, they have changed very little across their long history. Seasoned commentators may invoke imaginary time travellers reacting with bemusement at all that was familiar - as they entered the modern school gate. Yet such durability of design is not so exceptional. As a container for human activity, the modern school's design is, arguably, no more or less continuous with its past than that of, for instance, the shop, the hospital, the theatre, or the public house. All have iconic features that contribute towards their particular and recognisable senses of place. Yet, lately, the particular architecture and furniture of schooling has been actively addressed for reform (Dudek, 2000; Montazami, Gaterell and Nicol, 2015; Woolner et al, 2007). Three related features of such design initiatives seem 
particularly important for present purposes. The first relates to the sensory impact of the overall school fabric: that is, the goal of achieving "...a pleasant and comfortable environment for learning and to use architectural and design features to stimulate children's imaginations" (DfES, 2002). There is evidence suggesting that such overarching decor ambitions can make school a more inviting place for students to be (Rudd, Reed and Smith, 2008). Second, design can focus on the straightforward aim of improving the provision of subject-related technical resources (more laboratories, studios, gymnasiums etc. and an attendant provision of artefacts). Third, the structure of educational space can be re-considered in relation to its support of social interaction.

To simplify: these re-configurations work through, respectively, inspiring, equipping, and socialising. The last case is particularly interesting because it is in the social domain that the culture of educational practice may be judged to have undergone a particularly great historical change. To return to our time traveller: while they might find the details of a modern school's décor, furniture, and toolkit mildly surprising, what might be most unexpected is the changing social relations apparent within the school (and doubtless also the modern shop, hospital, theatre and pub). That is, the differences in how people interact with each other, yet do so within the frame of a stable architecture. Accordingly, where designers now seek to most disturb the status quo is in relation to the spatial structuring of this social interaction - the very same interaction that the designers of online learning are also at pains to disturb by their introduction of a very different infrastructure.

In contemplating the developments that are most intriguingly disruptive in this respect, it is easy to adopt a décor-centric perspective and overlook the involvement of new digital technologies. In the following sections we discuss the involvement of those technologies to re-configure copresent learning experiences, both 'spatially' and 'socially'. We provide examples in relation to: first, the support of the various collaborative structures for learning; second, the organisation of expository interaction between teacher and student; and, third, the facilitation of developing bonds of sociality within communities of students.

\subsection{Collaborative patterns}

In the slipstream of a multi-national 'building schools for the future' period (UK: Building Futures, 2004; DfES, 2004; Australia: McShane, 2012; Portugal: Blyth et al., 2012; US: Dortch, 2013), it may appear that furniture and its configuration holds the necessary key to re-mediating the social interactions of learning. However, digital technologies are also implicated. Here we highlight two ways in particular. The first is the more straightforward: classroom technologies can furnish focal points around which collaborators can interact - as well as opening communication links to groups working elsewhere. A current example of such an initiative is the NiCE Discussion Room ${ }^{2}$ (Haller et al., 2010), which integrates digital and analogue and paper tools into a cohesive communication system. A second, more subtle, way in which technology is

2 http://mi-lab.org/projects/nice-discussion-room/ 
implicated in configuring social space arises from the increasing adoption of small, mobile and often personal digital devices within particular spaces.

One clear example of this influence is the growth of 'learning commons' within the library facilities of universities (Beagle, 2012). The design effort in such places often seems concentrated on décor or furnishings that serve to render the space convivial and comfortable. Therefore the way such spaces ostensibly 'work' as contexts for collaboration is through allowing student users to mingle in more or less self-organising social patterns. However, it is portable technologies that have been observed actually to facilitate such a flux, by virtue of the ease with which they allow individuals and groups to convene and separate around these devices as personal and shared work resources (Crook and Mitchell, 2012).

However, this process of self-organisation is yet more strikingly visible when it is considered in the more traditional educational context of the school classroom. Figure 1 refers to previously unpublished data from a field study of secondary schools in which teachers generated 85 logs of lessons that involved tablets or laptop computers (Crook et al., 2010). Included in what was recorded was a visual map of the classroom (assembled by dragging icons into PowerPoint slides that were shared with the researchers). Students (green dots) were variously organised by teachers (blue suns) around surfaces (grey) and devices (yellow). The formats for those congregations echoed configural distinctions suggested elsewhere (Thornburg, 2013) and they are indicated in each row of the Figure. We typically think about mobile devices in terms of their journeying across a wide range of physical contexts, along with their owners. Yet here it seems evident that the mobility of devices has come to exert considerable influence over social organisation even within narrower and bounded spaces - and in ways that variously work with or across those forms of organisation implied by the existing design of the room or the configuration of the furniture. This local portability of technology serves to provide new opportunities for how we inhabit bounded and potentially rather constraining settings - those where the designed potential for flexibility is rather limited (a classroom in our example). The constraints in such settings are, as we have noted, those that have come to be a source of sustained concern for educational theorists. Furthermore, teachers and students alike do seem alert to some of those opportunities. Figure 1 provides examples that illustrate the range of formats observed. 


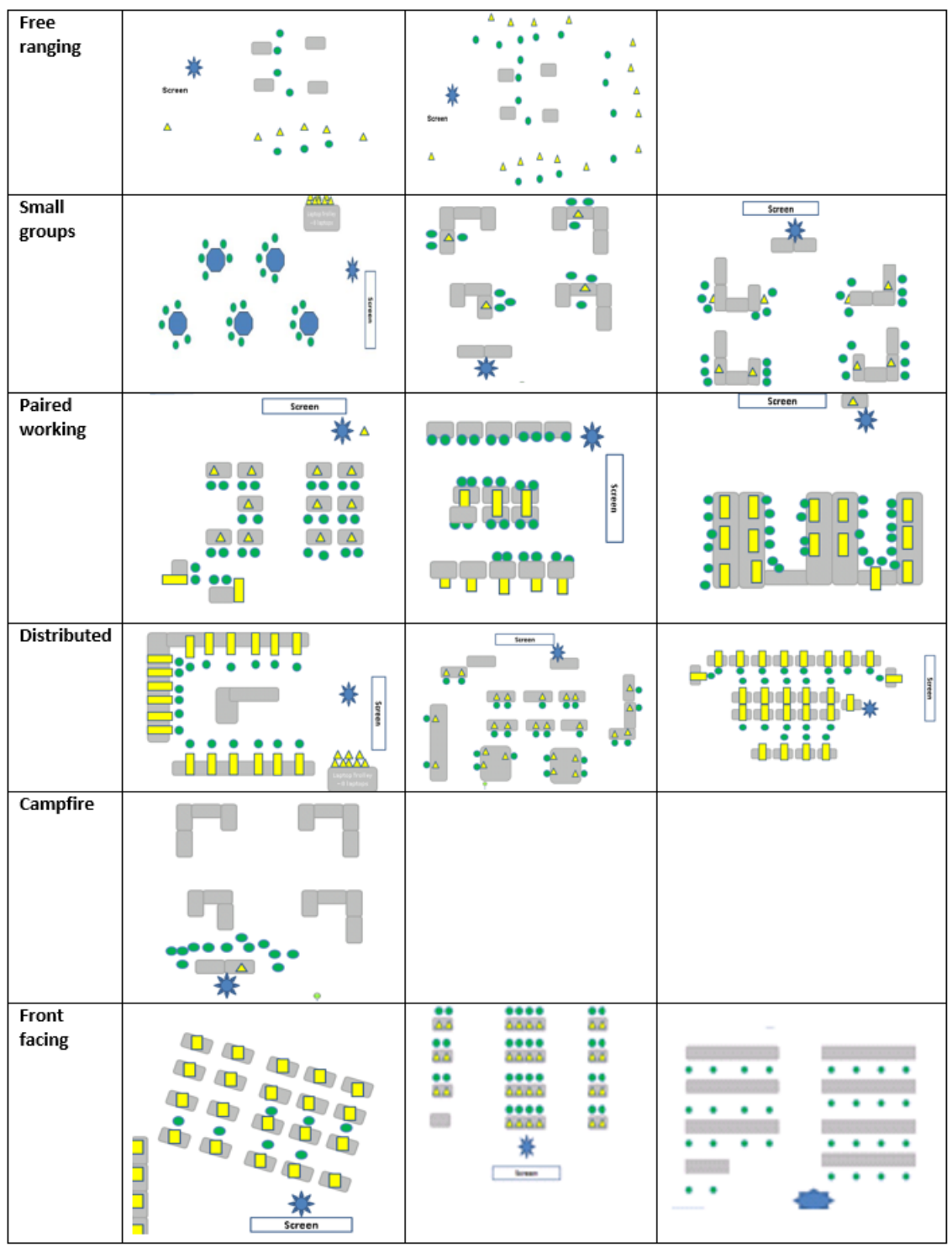

Figure 1: Classroom patterns of social learning mediated by mobile digital resources

In discussing the pedagogic potential of new technologies, Hamilton and Friesen (2013) have argued against essentialist and instrumentalist conceptions of impact. Similar warnings might be applied to considerations of spatial designs and their significance. Essentialism imbues technology with absolute qualities while instrumentalism prioritises the goals of users over the functional designs of technology. For both space and technology (and, in the present case, their intersection) a more useful perspective is a constructivist one. This perspective would understand pedagogies as an emergent process whereby social configurations for learning reflect prevailing, if implicit, values.

What is interesting within the images of Figure 1 is the way in which a very sparse space can be flexibly re-purposed. However, this is afforded by the ability of participants to self-organise: to convene around highly mobile study technologies (tablets and laptops). In our study we observed this in a variety of forms: the animated buzz of a class coordinating an online 
newspaper (free ranging); what by now might be considered traditional collaborative problem solving (small groups); peer mentoring around an e-portfolio (paired working); individual problem solving tasks tutored by a roving teacher (distributed); teacher orchestrating tasks for newspaper production (campfire); and building common knowledge via the whiteboard at the start of a lesson (front facing).

Let us return, briefly, to our interest in the sociality of learning. The configurations set out in Figure 1 illustrate a range of new ways for people to 'come together' to achieve shared understanding. Those 'new ways' are, perhaps, not always congruent with how those who designed the room (or laid out its furniture) anticipated that the room might be used; and it is far from certain that those designers would even approve of the change. Our discussion of online learning, above, pointed out how one apparent reason for success is an alignment with concerns about sociality seen as rebelling against established educational orders that require 'facing the front'. Here, we can see that technology is quite able to re-mediate some of those established practices even within localised space, providing students the opportunity to take advantage of resources both online (via the device) and local (by sitting, standing or crouching next to other members of their cohort). In terms of our focus on situativity, it is worth noticing two aspects of practice that are implied within the Figure. Firstly, the knowledge objects to which students gain access are potentially not only different virtual and material artefacts side-by-side, but are plausibly hybrid virtual-material objects - perhaps displayed on a device but also visible simultaneously within the same space by some sub-group of people, who can watch how the owner of the device manipulates some representation or potentially manipulate that representation collaboratively, encouraging particular kinds of discourse and close forms of collaboration. Secondly, it is worth highlighting that how students are working in the various examples involves actions that to varying extents borrow on practices familiar from formal education (collaboratively working on formally specified tasks), online education (exploring simulations, participating in online communities), informal learning (browsing for information, seeking connections to personal life) and what are increasingly becoming accepted work practices - coming together with others in ways that are plausibly somewhat ad hoc, to solve a particular problem together before dispersing into another configuration or to another venue. While the fact that our data was provided by teachers blunts our ability to enquire into how 'selforganised' were some of those configurations, it does seem plausible that one 'invariant' aspects of practice that such scenarios offer to students is experience in precisely those forms of episodic, quasi-serendipitous interaction that characterise various forms of contemporary 'knowledge working'.

Earlier it was noted that the design of schools has manifest a certain durability. Perhaps the challenge of creating an emancipating learning space is not so much a matter of the study furniture or atria that currently dominate design. The important thing is how interaction gets orchestrated within space - space which itself may continue to look rather familiar to metaphorical time travellers. As the present example highlights, technology can play a useful role in that orchestration: offering new possibilities for the teacher to consider when organising groups, making practical a wider range of options for students to consider when organising themselves, and in some cases influencing the physical configuration of people so as to dis-place more established centres of attention in the room. We emphasise, however, that where we say that the space might be sparse, where we say that learners might overcome the designed 
potential of space, where we emphasise that technology can play a useful role in that overcoming - none of that implies that space doesn't matter. The variety of configurations represented in Fig. 1, and the effort underpinning the creation of each of them on the part of teachers and students, are a testament to that.

\subsection{Expository patterns}

The collaborative learning patterns in the example above came about through a self-organising motive which, in turn, depended upon a freedom of movement coupled with the availability of mobile learning resources. In this section we turn to a different form of social configuration one that involves teacher and student in an expository relationship, and where the technology we focus upon is fixed in position. Although expository teaching is normally imagined as a sedentary, still, and passive social relationship, we suggest it actually shares with the previous case a dimension of movement, albeit one less immediately conspicuous. In this case the motion pattern of sociality is one of visual attention rather than of the more classic, ambulatory kind. The teacher's management of overt attention helps construct an implicit social exchange with the students, one in which the role of students is more or less active, if sometimes clandestinely so. First it will be useful to reflect on why exposition might be animated in this sense, before suggesting how it might be.

Exposition is a form of educational practice seen at risk of stifling student autonomy, collaboration, and discovery. Consider how the presentation of such spoken narratives typically work - perhaps by focussing on five practice elements in particular. First, the line and the sequence of argument are premeditated. Second, the sequence and pace is largely under speaker control. Third, speaker and listener are roles that people find difficult to relinquish. Fourth, the gazes of listeners are oriented within the room, front-facing, as though pulled by gravity. Fifth, the speaker's exposition is invariably mediated (as discussed below) by a limited tool that typically displays visual support. Such a scenario encapsulates many of the problems of schooling invoked at the outset of this paper. It is useful here to scrutinise that fifth element of practice - the visual mediation. If technology currently mediates the teacher-student dialogue of exposition in particular ways, might new tools mediate this practice differently? This meditational influence of tools may be considered in relation to the iconic expository case of the slideshow presentation, which has received considerable attention in the literature.

Let us consider some standard practices, as they have been conceptualised within that literature. The use of slide templates and the organisation of a slide structure together influence the preparatory shaping of thoughts and, in turn, how speakers act in front of their audience (Fagerjord, 2005; Tufte, 2006). Moreover, speakers using slideware in educational settings find it difficult to adjust their flow in real-time, or to respond to the unexpected (Adams, 2006). It is straightforward, then, to understand why the sequence and pace of exposition tend to remain under the control of teachers - even if that 'control' is not something that the teacher desires or about which they are conscious. A frequent separation of 'evidence' material from 'analysis' material within the slide deck - noticed by Tufte (2006), who explains the phenomenon partly in terms of the low information resolution of individual slides - seems further compounded by the synchronisation of speech with image during teacher exposition. One reason (among many) for 
listener reticence to construct and voice 'autonomous' vantage points might be that the content of the slide that is currently displayed has been chosen to support the current moment within the verbal argument; those visual materials on earlier slides that might resource alternative interpretations have already disappeared. The fact that the exposition is thus more or less controlled serves to implicate the teacher as one centre of attention. Yet the directionality of listeners' attention is further reinforced by a perception that the entire practice is set up, socially to be an interaction between speaker and visual materials-materials that are captivating to the eye even if sometimes boring to the intellect. That social 'set-up', which implies that listener quietude and speaker animation is not an aberration but the proper order of things, is part of the sense of place - and one that it would be educationally productive to overcome.

One consequence of the above is that teacher exposition can be narrowly deictic, based around the identity of an orator (Bligh \& Lorenz, 2010a). At different moments, that orator might seek to use their corporeality, such as when gesturing towards elements within slides; at others, they might choose to become a disembodied narrator of those slides. The role of listener in such a situation might be best understood not as inactive but as more or less strictly reactive. Yet, if this reactivity has been shaped by technology and the familiar conventions of place, surely it can be re-shaped if that technology and those conventions are destabilised? 


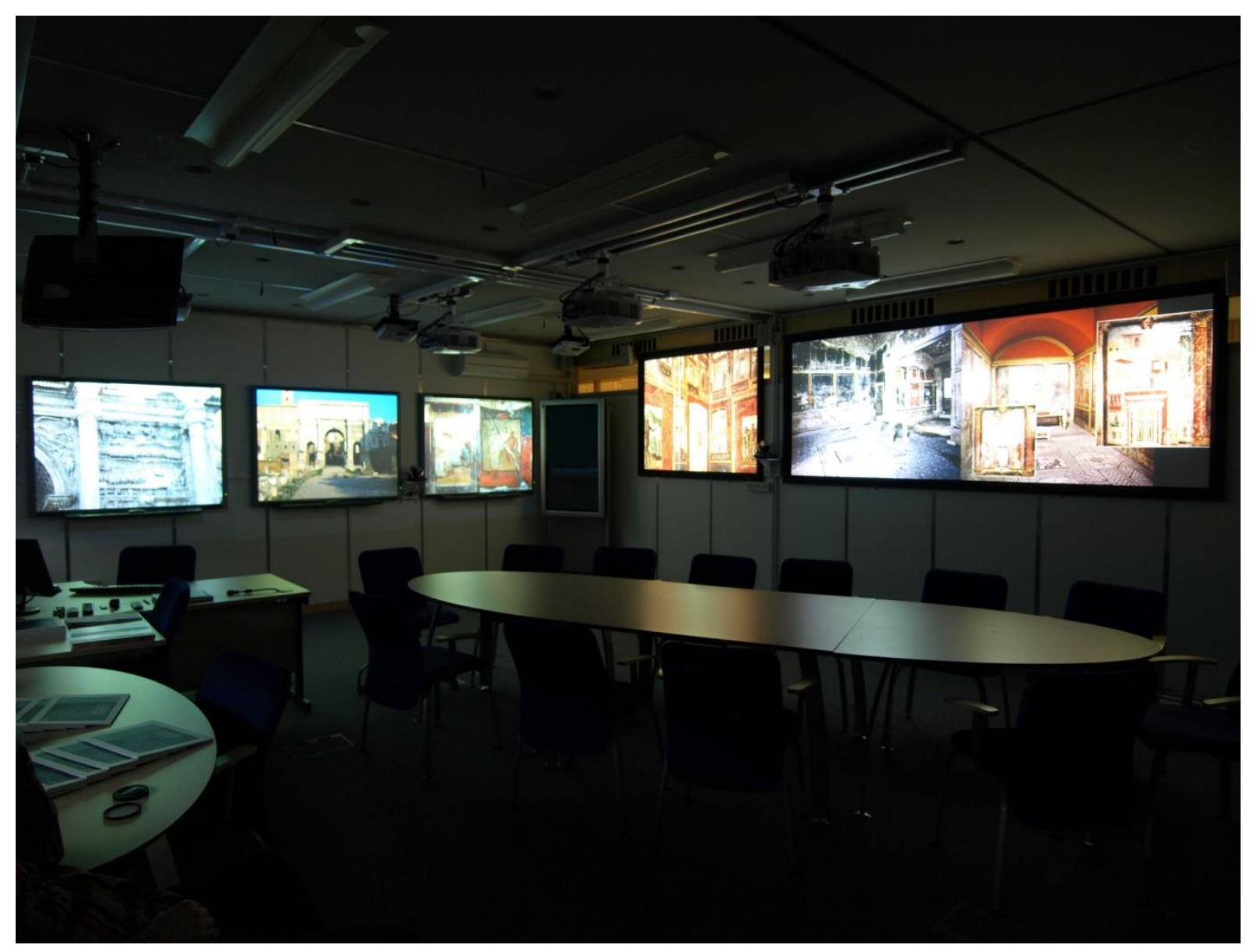

Figure 2: Distributing slides around a space

So: how might different forms of expository practice be more closely aligned with those aspirations for educational practice that we have considered above? One relatively straightforward scenario highlights several potential implications for new forms of visually mediated exposition, and also has implications for spatial design. In terms of technological prerequisites, that scenario involves a set of six projection screens, mounted across two walls of a teaching room, as shown in Figure 2. A Microsoft PowerPoint plug-in cascades slide content across the screens in a particular order. How might simply distributing slides around a space in this way serve to mediate exposition differently? We draw on the observational work of one of the present authors to address that question (Bligh \& Lorenz, 2010a; Bligh \& Lorenz, 2010b).

Let us consider this configuration starting with our second element of expository practice, the sequence and pace of argument. In those observed classroom interactions, although the order of the particular slides remained fixed, the sequence of the attendant argument was loosened to become more episodic than strictly linear - with a slower, more contemplative verbal narrative, referencing content back-and-forth across many of those slides currently being displayed. The teacher's comparing and contrasting of materials on different slides, by pointing, moving position and using a laser pointer, was revealing for students of that teacher's thought. This, in 
turn, had consequences for the roles of speaker and listener (the third practice element). The synchronisation between image and the speech of the teacher had been loosened, and with it some of the forbidding authority of the narrative. Moreover, each argumentational episode explicitly allowed for both verbal exposition by the teacher and a response by students. The number of available visual elements, and the even larger number of potential combinations, provided ample resources for students to discuss aspects and make comparisons that had not been mentioned by the teacher-and to do so using borrowed mechanisms such as pointing (and, with increasing frequency, actually by borrowing the teacher's laser pointer).

The preceding comments about pointing, movement, comparison and contrast are in themselves indications that the strongly directional gaze of listeners (that is, our fourth practice aspect of teacher exposition) was productively disrupted within this novel scenario. The teacher worked to direct attention around the room in different ways, and she herself likened the experience to touring with students round an art gallery rather than being in a classroom - certainly an indicator that place conventions were being disrupted, and partially replaced by new ones ${ }^{3}$. On those occasions where the teacher chose to walk behind all the students, there were marked differences in where students chose to turn and look - some of the conventions of expository practice had certainly been destabilised. As we highlighted above, it may be the case that the close coupling between a teacher's visual evidence and narrative exposition in more typical presentations serves to mediate a form of knowledge construction that is strongly directional and that discourages autonomous thinking. With that in mind, such independence of gaze can be interpreted as indicating a corresponding independence of narrative construction - as students seek out alternative evidence, consult again evidence presented earlier in the exposition, or try to find relations between the individual representations currently being displayed that are alternative to the ones being highlighted by the orator. We might say that the quality of social dialogue in the exposition was thereby resourced. The tutors' own construction of narrative was loosened: that is, more embodied in movement, and more directly comparative between resources rather than descriptive of them. While, at the same time, students' construction of autonomous views was moved - from the realm of the mental to the (more directly shared) realm of verbal contribution, gesture and a choice of where to direct the gaze.

We hope that we have conveyed how this design served to influence the sociality of learning: a sociality created by presenting multiple resources, by posing problems in more comparative ways, and by encouraging more overt participation in the social construction of exposition. But what of situativity, or more precisely what we have set up as the 'knowledge-building situativity' of educational places? The actual resources presented to students in this expository design were mostly photographs: of artefacts, museum catalogues, outdoor locations of archaeological interest, and so on. Visually attractive, for sure - but as 'representations' perhaps falling some way short of that problematic term authenticity. In fact, such relations between the

Since the material being taught was within a visual art discipline, the implications of this "art gallery" analogy are interesting as an indicator of what might happen when learning is displaced - there is an opportunity for appropriating senses of place from elsewhere. In another study, the author examined the use of a similarly novel (though not identical) display space on a Masters-level Architecture course, where the sense of place thus appropriated was one of a professional "client briefing" presentation (Bligh \& Coyle, 2013). 
'representation' and the 'authentic' were critiqued within the exposition itself, by both teacher and students. For example, spatially juxtaposing a mid-shot of an artefact against several closeups allowed the narrative of that artefact to be understood as a story of production ('authentic' thereby constructed as ancient workshop). Juxtaposing images of artefacts against aerial photography of real locations (such as a ruined Roman grotto) invited narratives placing the artefacts in their 'intended' locations or of tracing their discovery ('authentic', respectively, constructed as grotto as in antiquity or archaeological dig site). While, finally, the discussion of the classroom as art gallery perhaps says something about what that particular field of enquiry sees as the optimal location for learned disciplinary discourse ('authentic' constructed as art gallery). In our previous example, technology allowed for the relatively self-managed configurations of learners to emerge. In this example, it is the provision of resources in constellations that allow for the direct critique of contexts by learners themselves - which then allows those learners to overcome context dependency (our distinction between 'strong' and 'knowledge building' forms of situativity, above). To return to our initial vocabulary, the engagement of study has been deliberately re-mediated, the exposition of schooled knowing made more overtly participative, the schooled knowledge opened to challenge, and the cultural practices that constitute 'education' linked to a variety of locally understood outside sources of 'authenticity' - in productively contested ways. Moreover, this has occurred not only within the school but actually within a particular sub-unit of the school: the classroom. Next, we turn to examine how technology might contribute to destabilising the role of that iconic sub-unit.

\subsection{Beyond the classroom: community patterns}

In the previous two sections we have considered how new technology re-mediates the social relations of learning by creating new configurations within which participants can convene, at a highly localised scale. Discussion has considered two key social dynamics of classrooms: peer collaboration and teacher exposition (although, of course, these may often blend). In the first case, we illustrated how technology mediated a self-organising configuration of location within group collaborative learning; in the second case, how technology mediated a mobility of attention within the implicit dialogue of teacher exposition. A persistent aspiration within such schooled encounters must be the construction and elaboration of shared knowledge (Edwards and Mercer, 1987). While the above social configurations of the individual classroom may be readily oriented towards this goal, it is important to consider how the embedding of those traditional classrooms in overarching social structures - learning communities - serves further to support that effort, in the sense that is much celebrated for virtual spaces of educational practice. Once again, we wish to examine a particular form of this embedding that remains located within a conventional site of learning - the school building and its ongoing development as a place for a community with a shared history.

One example of school design where teachers and students work together to construct these places with shared histories is the Small Learning Community (SLC). SLCs are constellations of spaces within a wider school, arranged to serve as a semi-permanent home for between 80 and 150 students (Nair, Fielding and Lackney (2009) document numerous examples from several countries). They are typically centred on learning studios, L-shaped classrooms designed to support multiple centres of action. Supporting spaces-including small breakout rooms, 'messy- 
work' laboratories, storage areas, and kitchens-are placed around those learning studios. Within a particular SLC, the aim is to support the emergence of bonds of sociality within a community of students, bonds that might endure over considerable periods of time. Relationships between students and members of staff are unconventional within SLCs: several teachers are assigned to supervise several groups of students, intervening on a roving basis to assist groupwork rather than leading classes; the allocation of spaces to student groups is approached democratically rather than by timetabling diktat; and the movement of wheelmounted furniture, undertaken to reconfigure rooms, is a shared venture that requires communal negotiation. Nair et al. (2009) suggest that SLCs ought to serve as the new unit of schools; their broader aim is that schools come to be seen as collections of SLC neighbourhoods, rather than collections of classrooms. Within this model, particular SLCS are to be connected by learning streets that provide spaces for solitary study and serendipitous interaction as well as fulfilling their more traditional role as routes of circulation.

One way in which technology may be recruited into this structure is by provisioning a distribution of specialised spaces across the community hub - to include particular spaces set out as, for example, corporate board rooms with presentation technologies, media production suites with powerful computers and specialist software, or performance spaces with configurable projectors, sound equipment and stage curtaining. It is worth noticing how it is the distribution of those technological resources within those smaller spaces that to some extent circumscribes their specialism as 'places'. Particular spaces can and do exhibit some flexibility in their configuration, but the SLC hub most conspicuously invites a fluidity of movement from (local) place to (local) place - and anticipates that the patterns of that movement will be more or less governed by students themselves. The aim is that the same students and teachers spend a majority of their time at school within the same hub - which becomes 'their' community space but not necessarily fixed within particular rooms within that hub. It is envisaged that the collection of spaces overall becomes gradually reconfigured for their needs, to a great extent by their own action, and that the information exhibited around the walls comes to reflect the history of community activity.

It is clear that many of those scenarios within the individual rooms invoke familiar cultural practices from the surrounding society and culture - perhaps importing such recognisable forms of place in the hope of cultivating the attendant practices more authentically.

However, notice the complexity of the manner in which those practices and sense of place are encapsulated. Creating relatively stable communities of around 150 people consciously renders the school as a community somewhat smaller than it is as an institutional entity. Yet the unit of space becomes larger than the single classroom. There is clearly no straightforward relationship between the size of some space (in square metres) and the forms of communal sociality that will occur there. The vocabulary used to describe SLCs perhaps implies only some of this shifting, complex encapsulation. Nair, Fielding \& Lackney (2009), for example, variously describe SLCs as being like neighbourhoods supporting a family ${ }^{4}$, while they denigrate the assignment of

Once again, we note that the choice of these metaphors is interesting in its idealisation. By invoking the word 'family', we assume that the proponents of SLCs wish to create the sense of mutual dependence and a human scale for relationships. We assume that the attendant 
individual classrooms by central timetabling as having the demeanour of cells (invoking a prison metaphor). What is perhaps underemphasised is the intended permeability of the small community's external boundaries. SLCs designs often carefully encompass aspects of the outdoor school environment but not of the surrounding locality outside the school. We might say that the intention is, quite literally, a 'walled garden', in which the resources provided for (and by) the community to some extent preclude the need for learners to connect with the outside (cf. Malone, 2007). From the vantage point of our discussion of 'knowledge building situativity', questions about how learners overcome the contextual bounds of the place in which they are constructing knowledge are as yet unanswered - though they are not, in principle, unanswerable. Once again, we note that this discussion of walled gardens is a familiar part of the discourse about online learning, where a desire for child safety has often underpinned the provision of institutional platforms - platforms that frequently prove unpopular with learners. So this is a situative 'restriction', perhaps deliberately created, that has something in common with particular designs for online learning. Yet, on the other hand, some of those forms of sociality and situativity that the SLC is designed to support have a rather different tenor from those intermittent and often textual forms of online collaboration that characterise much online learning. They entail the co-presence of people undertaking different tasks, a culture of volunteering to help out other groups serendipitously in the same space, a spillover of sound between areas (supporting an ambient awareness of wider communal efforts), the collective movement of furniture and the preparation of space for future endeavours, a mixing of workspaces and those used for leisure and for consuming food, and the conscious mimicry of established cultural venues. We might say that this is a form of learning dis-placement that invokes, for better or worse, a localised - even agricultural - notion of culture and socialisation, one tied quite closely to its land.

\section{Looking forward}

The discussion in this paper has been prompted by the growth of enthusiasm for educational experiences that are dis-placed from the materiality of traditional educational sites and reconfigured in virtual spaces - colloquially, we might say that this represents a dis-placing of 'bricks to clicks'. The intention has been to create a counterpoint to that possibility rather than an outright challenge - to notice that such dis-placing need not be understood in a totalising way, and is not synonymous with un-placing. It is admitted throughout that the social relationships of educational practice can, at this juncture, be usefully refreshed and animated in a range of ways. Our sketched examples above particularly highlight how digital technology can be creatively implicated in that process in ways that complement the physical rather than by imagining its abolition. The attendant configuration of social interaction can benefit from thoughtful spatial design. But the sociality of pedagogy does not flow simply from the form or placement of furniture. It is something that is constructed by participants and, moreover, technologies may play an important role in mediating that construction.

One source of our interest has been to investigate the prospects for embodied co-presence as a central feature of educational experience. When mapping possible futures, there is a distinction

patriarchal relationships and laws of property or inheritance are aspects of the metaphor that are not to be carried across - at least not intentionally. 
between what one desires and what one expects. Both commitments are troublesome. A weakness of much 'futures' work around learning is that it risks assuming a basically stable economic, cultural, macro-political, and psychological context within which educational experience should (or will) get shaped. This is surely unlikely. At the macro-cultural level there will be challenging and unpredictable forces of a political - and even of an ecological - kind. For example, consider the global imperatives of sustainability, the expanding corporate influence in the public sector, or perceptions of the tax burden of schooling on an increasingly ageing population: how will they evolve and thus shape society's choices for designing the conditions of learning?

Still more finely balanced are uncertainties of a more micro-political or psychological nature. For example, it is suggested (OECD, 2001) that one consequence of extended educational provision will be to decrease the 'distance' between schools and the important stakeholders who scrutinise them. So, heightened literacy amongst parents may lead to greater expectancy and demands for 'accountability'. That literacy may even further stimulate niche educational alternatives, such as more variants on home or faith schooling. Finally, considerations of the future must also confront changes in the basic motivations or developing cognitive structures of childhood and youth itself. Appetites manifest during early human development will be shaped by pressures for novel cultural and technological consumption. Those appetites may not always fit with the current ambitions (or future visions) of education and educators.

In short, it is very unclear how the patterning of such mixed tensions and alignments may develop. Any anticipation of re-invented places for learning has to struggle with predicting the changing ecology, economy, technology, and even psychology of the society within which learners are situated. Furthermore, we should anticipate a similar degree of contestation at the more 'micro' levels of spatial design and inhabitation. In the present piece we have focussed most directly on the issue of dis-placing learning. Doing so highlights the destabilising effects of technology, which can be productively appropriated, and some sources of commonality and tension between discourses of online learning and the changes unfolding in the more conventional settings of school. Yet 'senses of place' are not the only sites of struggle pertinent to understanding relationships between physical spaces and learning. Elsewhere, for example, as well as place metaphors, we have highlighted the importance of focussing critically on a range of other spatial influences on educational processes - how space might stimulate creativity or inspiration, how aspects of space are incorporated into learners' cognitive processes, how particular physical designs for space both encourage and impede particular forms of action, how institutional standards for spaces can support commonality of action (while placing a power to restrict the drive for idiosyncratic or distinctive spaces into particular hands), and how spaces come to be adapted and owned by communities on an ongoing basis (Bligh \& Crook, in press). It is not simply that the resolution of those tensions is difficult to predict: rather, their resolutions are likely to be local, temporary, and subject to continual struggle. Perhaps the most useful approach in contemplating spatial 'futures' is therefore to map out the likely contours of those struggles rather than seeking to predict some outcome.

In reflecting on the emergence of the increasingly 'smart' classroom, Scardamalia and Bereiter (2014) comment: "There needs to be some glue. The glue nature gave us is discourse." While we broadly agree with that view, there is an attendant necessity for those designing educational 
scenarios to explicitly broaden their conception of the term 'discourse' beyond common-orgarden understandings that focus on the spoken (and, to a lesser extent, the written). We hope that in this paper we have demonstrated the possibility for learning to be dis-placed by technology in ways that continue to take advantage of aspects of sociality and situativity in realms of discourse that go beyond the spoken and written modes that so dominate online interaction - and, equally importantly, in ways that might complement those modes. Such displacing might involve enabling a freedom of movement that circumvents the intentions of space designers; a shared experience of exposition supported by bodily movement, and the opportunity for alternative explanations to be constructed; a communal camaraderie implicated in the ongoing shaping of space and the exhibition of previous endeavour; and confronting the

difficult dilemma of placing boundaries on learning that include and nurture while also excluding (and protecting?). In short, we have argued that dis-placing is not un-placing - that technology certainly serves to destabilise some of the conventions of learning in interesting and sometimes productive ways, but does not render the notion of place obsolete.

\section{References}

Adams, C. (2006). PowerPoint, habits of mind, and classroom culture. Journal of Curriculum Studies, 38(4), 398-411.

Appelman, R. (2004). Designing experiential modes: A key focus for immersive learning environments. TechTrends, 49(3), 64-74.

Autor, D. H., Levy, F., \& Murnane, R. J. (2003). The skill content of recent technological change: An empirical exploration. The Quarterly Journal of Economics, 118(4), 1279-1333.

Aydede, M., \& Robbins, P. (Eds.). (2009). The Cambridge handbook of situated cognition. New York, NY: Cambridge University Press.

Beagle, D. (2012). The emergent information commons: Philosophy, models, and 21st century learning paradigms. Journal of Library Administration, 52(6-7), 518-537.

Benjamin Jr., L.T. (1988). A history of teaching machines. American Psychologist, 43(9), 703-712.

Bereiter, C. (1997). Situated cognition and how to overcome it. In D. Kirshner \& J. A. Whitson (Eds.), Situated cognition: Social, semiotic, and psychological perspectives (pp. 281-300). Hillsdale, NJ: Erlbaum.

Bligh, B. \& Coyle, D. (2013). Re-mediating classroom activity with a non-linear, multi-display presentation tool. Computers \& Education, 63, 337-357.

Bligh, B. \& Crook, C. (in press). Learning Spaces. To appear in: E. Duval, M. Sharples \& R. Sutherland (Eds.), Technology enhanced learning: Research themes. Dordrecht: Springer.

Bligh, B. \& Lorenz, K. (2010a). The rhetoric of multi-display learning spaces: exploratory experiences in visual art disciplines. Seminar.net: International Journal of Media, Technology and Lifelong Learning, 6(1), 7-27. 
Bligh, B. \& Lorenz, K. (2010b). Vorprung durch Technik: Multi-Display Learning Spaces and ArtHistorical Method. In A. Bentkowska \& J. Pilcher (Eds.), Technology and 'the death of Art History': Proceedings of the Computers and the History of Art (CHArt) Annual Conference, British Computer Society, London, 10-11 November 2010. London: CHArt.

Blyth, A., Almeida, R., Forrester, D., Gorey, A. \& Hostens, G. (2012). Modernising Secondary School Buildings in Portugal. OECD. Retrieved February 1, 2016 from http://www.oecd.org/edu/innovationeducation/centreforeffectivelearningenvironmentscele/49567409.pdf.

Bowles, S., and Ginitis, H. (1976). Schooling in Capitalist America: Education Reform and the Contradictions of Economic Life. New York: Basic Books Inc.

Brown, J.S., Collins, A. and Duguid, P. (1989). Situated cognition and the culture of learning. Educational Researcher, 18(1), 32-42.

Building Futures. (2004). 21st century schools, learning environments of the future, a joint initiative between CABE and RIBA. London: Building Futures. Retrieved January $20^{\text {th }} 2016$ from http://webarchive.nationalarchives.gov.uk/20110118095356/http:/www.cabe.org.uk/files/21stcentury-schools.pdf

Butler, L. P., \& Walton, G. M. (2013). The opportunity to collaborate increases preschoolers' motivation for challenging tasks. Journal of Experimental Child Psychology, 116(4), 953-961.

CBI (2009) Future Fit: Preparing Graduates for the World of Work. London: Confederation of British Industry Higher Education Task Force.

CBI (2012) First Steps: A New Approach for our Schools. London: CBI.

Claxton, G. (2013). What's the Point of School?: Rediscovering the Heart of Education. Oxford: Oneworld Publications.

Cole, M. (1990) Cultural psychology: A once and future discipline. In J. Bergman (Ed.), Nebraska symposium on motivation: cross-cultural perspectives (pp. 279-336). Lincoln: University of Nebraska Press.

Collins, A., Brown, J. S., \& Newman, S. (1989). Cognitive apprenticeship: Teaching the craft of reading, writing, and mathematics. In L. B. Resnick (Ed.), Knowing, learning and instruction: Essays in honor of Robert Glaser (pp. 453-494). Hillsdale, NJ: Erlbaum.

Crook, C.K. (1994) Computers and the collaborative experience of learning. London: Routledge.

Crook, C., Harrison, C., Farrington-Flint, L., Tomás, C. \& Underwood, J. (2010). The impact of technology: Value-added classroom practice. Final Report. Coventry: Becta.

<http://oro.open.ac.uk/34523/1/the_impact_of_technology.pdf>

Crook, C. and Lewthwaite, S. (2010). Technologies for formal and informal learning. In K. Littleton, C. Wood, \& J.K. Staarman (Eds.), International Handbook of Psychology in Education (pp. 435-461). Bingley: Emerald. 
Crook, C.K. and Mitchell, G., (2012). Ambience in social learning: student engagement with new designs for learning spaces Cambridge Journal of Education. 42(2), 121-139.

Damon, W. (1981). The social world of the child. San Francisco: Jossey-Bass.

DfES (2004). Building schools for the future: A new approach to capital investment, DfESD

Donald, M. (1991). Origins of the modern mind: Three stages in the evolution of culture and cognition. Harvard University Press.

Dortch, C. (2013). School construction and renovation: A review of federal programs.

Congressional Research Service. Retrieved on February 12016 from

https://www.fas.org/sgp/crs/misc/R41142.pdf..

Drucker, P. F. (1992). The age of discontinuity: Guidelines to our changing society. New Brunswick (U.S.A.): Transaction Publishers.

Dudek, M. (2000). Architecture of schools: The new learning environments. Oxford: Routledge.

Edwards, D., \& Mercer, N. (1987). Common knowledge: The development of understanding in the classroom. London: Methuen.

Fagerjord, A. (2005). Prescripts: authoring with templates. Kairos, 10(1) [online]. Retrieved on June 32015 from

http://kairos.technorhetoric.net/10.1/binder2.html?coverweb/fagerjord/index.html.

Freire, P. (1986). Pedagogy of the oppressed. New York: Continuum.

Gee, J. P. (1992). The social mind: Language, ideology, and social practice. New York, NY: Bergin \& Garvey.

Gee, J. P. (2004). Situated language and learning: A critique of traditional schooling. Psychology Press.

Goodfellow, R. (2007). From "equal access" to "widening participation": The discourse of equity in the age of e-learning. In J. Lockard \& M. Pegrum (Eds.), Brave new classrooms: Educational technology and democracy (pp. 55-74). New York: Peter Lang.

Goodyear, P. (2005). Educational design and networked learning: patterns, pattern languages and design practice. Australasian Journal of Educational Technology, 21(1), 82-101.

Greeno, J.G. (1997). On claims that answer the wrong questions. Educational Researcher, 26(1), 5-17.

Hagel, J. \& Singer, M. (1999) Unbundling the corporation. Harvard Business Review, March-April, 133-141.

Haller, M., Leitner, J., Seifried, T., Wallace, J.R., Scott, S.D., Richter, C., Brandl, P., Gokcezade, A. and Hunter, S. (2010). The NiCE discussion room: integrating paper and digital media to support collocated group meetings. In E. Mynatt, G. Fitzpatrick, S. Hudson, K. Edwards \& T. Rodden (Eds.) CHI '10: Proceedings of the 28th international conference on Human factors in computing systems. Atlanta, GA, USA , April 10-15, 2010 (pp.609-618). ACM Press. 
Hamilton, E., \& Friesen, N. (2013). Online Education: A Science and Technology Studies Perspective/Éducation en ligne: Perspective des études en science et technologie. Canadian Journal of Learning and Technology/La revue canadienne de l'apprentissage et de la technologie, 39(2).

Heterick, R. C., Mingle, J. R. \& Twigg, C. A. (1998). The public policy implications of a global learning infrastructure. Report from a Joint NLII-SHEEO Symposium. Denver, CO, Nov. 13-14, 1997. Retrieved January 222016 from http://net.educause.edu/ir/library/html/nli0005.html.

Illich, I. (1971). Deschooling society. London: Marion Boyars.

Jandrić, P. (2014). Deschooling virtuality. Open review of educational research, 1(1), 84-98.

Johnson, D. W., \& Johnson, R. T. (1989). Cooperation and competition: Theory and research. Edina, MN: Interaction Book Company.

Katz, R. \& Oblinger, D. (2000). The ' $e$ ' is for everything: E-commerce, e-business and e-learning in the future of higher education. San Francisco: Jossey-Bass, Educause.

King, A. (1993). From sage on the stage to guide on the side. College Teaching, 41(1), 30-35.

Lave, J., \& Wenger, E. (1990). Situated learning: Legitimate peripheral participation. Cambridge, UK: Cambridge University Press.

Lundvall, B.-Å. (1992). National systems of innovation: Towards a theory of innovation and Interactive learning, London: Pinter Publishers.

Mahony, P. and Hextall, I. (2013), 'Building Schools for the Future': 'transformation' for social justice or expensive blunder?. British Educational Research Journal, 39(5),853-871.

Malone, K. (2007). The bubble-wrap generation: children growing up in walled gardens. Environmental Education Research, 13(4), 513-527.

McShane, I. (2012). Learning to share: Australia's Building the Education Revolution and shared schools. Journal of Educational Administration and History, 44(2), 105-119.

Miller, S.L. (2015). Teaching an online pedagogy MOOC. Journal of Online Learning \& Teaching, 11(1), 87-102.

Montazami, A., Gaterell, M., \& Nicol, F. (2015). A comprehensive review of environmental design in UK schools: history, conflicts and solutions. Renewable and Sustainable Energy Reviews, 46, 249-264.

Nair, P., Fielding, R., \& Lackney, J. (2009). The Language of School Design: Design patterns for 21st century schools. Second edition. Minneapolis, MN: DesignShare.

Prensky. M. (2001). Digital natives, digital immigrants Part 1. On the Horizon, 9(5), 1-6.

Putnam, R. D. (2015). Our kids: The american dream in crisis. Simon and Schuster.

Reimer, E. W. (1971). School is dead: Alternatives in education. London: Penguin.

Rizvi, F. \& Lingard, B. (2010) Globalizing education policy. Abingdon: Routledge. 
Robinson, K. (2006). Ken Robinson says schools kill creativity. Technology, Entertainment and Design Talks. Retrieved June $5^{\text {th }} 2015$ from http://www.ted.com/talks/ken_robinson_says_schools_kill_creativity.html.

Rudd, T., Gifford, C., Morrison, J., \& Facer, K. (2006). What if...? Re-imagining learning spaces. Bristol, UK: Futurelab.

Rudd, P., Reed, F., \& Smith, P. (2008). The effects of the school environment on young people's attitudes towards education and learning : Summary Report [Monograph]. Retrieved January 24, 2016, from http://eprints.whiterose.ac.uk/73960/.

Scardamalia, M., \& Bereiter, C. (2006). Knowledge building: Theory, pedagogy, and technology. In K. Sawyer (Ed.), Cambridge handbook of the learning sciences (pp. 97-118). New York: Cambridge University Press.

Scardamalia, M., \& Bereiter, C. (2014). Smart technology for self-organizing processes. Smart learning environments, 1(1), 1-13.

Searson, M., Monty Jones, W., \& Wold, K. (2011). Editorial: Reimagining schools: The potential of virtual education. British journal of educational technology, 42(3), 363-371.

Shantz, J. (2012). Spaces of learning: The anarchist free skool. In R. H. Haworth (Ed.), Anarchist pedagogies (pp. $124-144)$. Oakland, CA: PM Press.

Suchman, L.A. (1987). Plans and situated actions. Cambridge: Cambridge University Press.

Thornburg, D. (2013). From the Campfire to the Holodeck: Creating Engaging and Powerful 21st Century Learning Environments. John Wiley \& Sons.

Tomasello, M. (2009). The cultural origins of human cognition. Harvard University Press.

Tomasello, M., Carpenter, M., Call, J., Behne, T., \& Moll, H. (2005) Understanding and sharing intentions: the origins of cultural cognition. Behavioral and brain sciences, 28(5), pp. 675-735.

Upitis, R. (2004). School Architecture and Complexity. Complicity: An international journal of complexity and education, 1(1).

Vygotsky, L. (1933/1978). Mind in society: The psychology of higher mental functions. Cambridge, MA: Harvard University Press.

Warmington, P. (2015). Dystopian social theory and education. Educational theory, 65(3), 265281.

Wells, G. (1999). Dialogic inquiry: Towards a socio-cultural practice and theory of education. Cambridge, UK: Cambridge University Press.

Whitehead, A. N. (1929). The aims of education. New York: Macmillan.

Woolner, P., Hall, E., Higgins, S., McCaughey, C., \& Wall, K. (2007). A sound foundation? What we know about the impact of environments on learning and the implications for Building Schools for the Future. Oxford review of education, 33(1), 47-70. 
Young, M. (2015). What is learning and why does it matter? European journal of education, 50(1), 17-20.

Young, M., and J. Muller. (2010). Three educational scenarios for the future: lessons from the sociology of knowledge. European journal of education, 45(1), 11-27.

Zmuda, A., Ullman, D., \& Curtis, G. (2015). Learning personalized: The evolution of the contemporary classroom. John Wiley \& Sons. 